\title{
Pygmalion Effect on Junior English Teaching
}

\author{
Yurong Wang (Corresponding author) \\ College of Foreign Languages, Three Gorges University \\ 8 Daxue Road, Yichang City, Hubei Province, PA 443002, China \\ E-mail: 1058940294@qq.com \\ Li Lin \\ College of Foreign Languages, Three Gorges University \\ 8 Daxue Road, Yichang City, Hubei Province, PA 443002, China \\ E-mail: 786343846@qq.com
}

Doi:10.7575/aiac.alls.v.5n.6p.18

Received: 28/07/2014

URL: http://dx.doi.org/10.7575/aiac.alls.v.5n.6p.18

Accepted: 24/09/2014

\begin{abstract}
Pygmalion Effect, or Robert Rosenthal Effect, was proved by the famous American psychologist Robert Rosenthal and Jacobson in 1968. Pygmalion Effect, as a matter of fact, is a psychological suggestion, which believes that people can accept the influence and suggestion given by the people whom very much they admire, like, believe, and respect. This effect was first applied in the field of management and medication. What's more, remarkable achievements have been accomplished on human resource management. Robert Rosenthal put it into education through an experiment called Pygmalion in the Classroom, which aroused widely attention in the education sector. This thesis mainly focuses on the application of Pygmalion effect in English teaching, especially junior English teaching in China. If we can make good use of the Pygmalion Effect to conduct teaching and have positive expectations to students, it will improve teaching greatly.
\end{abstract}

Keywords: Pygmalion Effect; Management; Medication; English teaching; Application; function

\section{Introduction}

\subsection{The Background of the Study}

With the advent of globalization, people tend to pay more and more attention to English teaching and learning, for English is widely used and plays a dominant role in communication. For most people, they always expect to be encouraged and praised habitually. An affirmative suggestion, or encouraging words, always makes them feel full of fortitude. This is also true of language learning, or more specifically, English learning. Students need to be encouraged, just like plants need water. Lots of researches have been done by some professors on education, which has made a great contribution to English teaching and learning. Since 1970s, American famous psychologist Robert Rosenthal and Jacobson made an experiment and proposed Pygmalion Effect, which as a matter of fact, served as a kind of psychological suggestion, indicate that people can accept the influence and suggestion given by the people whom very much they admire, like, believe and respect.

Pygmalion Effect has been widely applied in medication, management, and other fields of scientific terms. Few studies about Pygmalion Effect on English learning are found in foreign language teaching. It is not until 1968 that Pygmalion Effect being used in education and psychology. This famous effect has made a great contribution to English teaching and there are still a lot of essences we can gain from it.

\subsection{The Purpose of This Thesis}

The students in junior middle school grade one start to learn English with great curiosity at the very beginning in China. However, it is really a prevalent phenomenon that when they enter into higher grades, they tend to have little interest in English learning, and what's worse, some students just regard it as a heavy burden. This is not only the students' fault; it also has something to do with English teachers. According to an investigation made by Lu Jiamei, a professor of Shanghai Normal University, only $80 \%$ of teachers take affective education into practice. How to improve the current situation of English teaching? Pygmalion Effect illustrates the higher expectations of teachers and students. The theoretical basis of multiple intelligence theory can directly affect the formation of a positive and optimistic teacherstudent view, that is, there is no so-called "poor students". The existence of every student is unique. Pygmalion Effect can make a lot of improvements in English teaching, with the teacher focusing on the students who seek and find the bright spot, discover and develop the potential of students.

\subsection{The Structure of the Thesis}

There are five parts under the thesis: part one introduces the background, purpose and structure of the thesis. Part two is a literature review, which sums up the relevant study conducted in Pygmalion Effect, covering its definition, origin, and development. It also includes the application of Pygmalion Effect in other fields, such as management, medication etc. 
The third part is about the practical function of Pygmalion Effect in junior English teaching, which includes three dimensions, that is the construction of a harmonious teacher-student relationship, the inspiration of students' intrinsic motivation of learning and the enhancement of confidence. The forth part is about the application of putting Pygmalion Effect into junior English teaching, which covers proper expectations, patient love, appropriate emotional communication and full respect. Finally, the fifth part is a conclusion.

\section{Literature Review}

\subsection{The Definition of Pygmalion Effect}

Pygmalion Effect is a case of self-suggestion and also self-expectancy which has been applied to researches in many fields in recent years (Wang Limei, 2008). "Suggestion is the simplest and the most typical conditioned reflex of human"(Zhao Yue, 2005).

Pygmalion effect is, in fact, a psychological suggestion. People can accept the influence and suggestion given by the people whom very much they admire, like, believe and respect.

It means that "you get what you expect". People tend to live up to what is expected of them. They tend to do better when treated as if they are capable of success(Su Ying, 2010).

When we expect certain behaviors of others, we are likely to act in ways that make the expected behaviors more likely to occur (Rosenthal \& Balad, 1985).

If we expect much of somebody and devote more efforts to him, it is much more possible for us to get the result which we have expected. The sculptor carved a statue of beautiful maid out of stone according to his imagination and hope. In fact, teaching is the process of "curving". Teacher is a sculptor and students are his works. So teachers also can educate the students whose outcome corresponds with teachers' expectations.

\subsection{The origin of Pygmalion effect}

This is a classical allusion of ancient Greek myth. There once was a king named Pygmalion in Cyprus at the ancient time. He was very good at curving. One day, he curved a statue of a beautiful maid to which he devoted all his passion and hope. He wished that the statue would come into life. During the process of curving, he was curving it exquisitely and refining on it again and again. At last, the king's dream came true. The statue became a beautiful maid mysteriously (Zhao Yue, 2005). Much later, George Barnard Shaw, a famous British playwright, wrote a play entitled Pygmalion. In this way, the conception of "Pygmalion" was first proposed from it.

\subsection{The Development of Pygmalion Effect}

Since 1970s, a famous American psychologist Robert Rosenthal introduced the conception of Pygmalion Effect into education and psychology, and therefore carried out a research named Pygmalion in the Classroom in 1968.

In the year 1968, Robert Rosenthal and Jacobson made an experiment on teaching. They selected some $20 \%$ students randomly in the class, and then told their English teacher that those 20\% students are the smartest of all the students in the class and they will be great people in the years to come. As a matter of fact, these students were the same with any other students. However, after Rosenthal's remarks, the English teacher had a special impression to those smart students and gave them more encouragement and guidance consciously or unconsciously during daily teaching. After 8 months, they did the same test again on all students. They found that these so-called "smartest students" really had advanced more in intelligence than others, and they had much strong desire to obtain knowledge and they had much strong adopting ability and charm.

Thereafter, Brophy (1983) conducted an experiment. He made a relevant analysis of teachers' expectations and students' final scores, which showed that teachers' expectations and students' scores are closely interrelated with each other.

In 1978, Daragh Murphy and Clifton Campbell made a paradigmatic research on 4300 children which lasted for four years, which also proved the former finding.

\subsection{The Application of Pygmalion Effect in Other Fields}

Pygmalion Effect was primarily widely used in management. The main problem in the level of enterprise management is to combine people who have different culture backgrounds, different status and different goals together and then create an optimal path for its development. However, how to make the enthusiasm of various types of personnel to be fully mobilized to form a joint force? Pygmalion Effect should be applied in the whole process. It shows that managers who expect more from their employees get more from them. When a leader expects subordinates to perform well, they do. The way managers treat their subordinates is subtly influenced by what they expect of them. Take Pygmalion Effect into full use, stimulate the morale of the staff and pose trust them, amazing benefits would be created. The Pygmalion effect enables staff to excel in response to the manager's message that they are capable of success and expected to succeed. Jack Welch, The CEO of General Electric, once said that the most important thing he did so far is to boost others' confidence. He is the one who has put Pygmalion effect into application. In human resource management, managers are required to become the opposite Pygmalion, to enhance employees' confidence gradually and to establish a sound corporate culture.

There is also a prevalent use of Pygmalion effect in medication in the process of clinical management. The application of Pygmalion effect can explore the potential of nurses; its unique rote cannot be ignored. In clinical work, managers' 
gentle comforting, encouraging words and warn eye contact will have great influences on nurses. In the same way, their care and encouragement could provide the tortured patients with confidence and fortitude. Passing patients positive suggestions, their psychological burden will be eased. Once formed a sound mental state, illness will more easily be conquered.

Put this effect into education, there still will be prominent improvements. Having received teachers' proper expectations, students always form some certain self-concept accordingly, that is, some certain education to their ability and intelligence etc. They will take action according to this self-concept. Psychological research indicates that students who have a strong sense of dependence will keep on further learning once being agreed and praised. However, the "praise" here is, as a matter of fact, the practical use of Pygmalion effect. Stepped into junior middle school, it is the first time for middle school students to face this brand new language, thus they are always highly dependent on their English teacher. In this regard, taking middle school students' age and psychological features into consideration, this thesis focuses on the function and application of Pygmalion Effect in junior middle school English teaching in China.

\section{The Function of Pygmalion Effect in Junior English Teaching}

Professor Wang Chuming (2005) pointed that "Foreign language teaching and learning is a psychology war" which implicates that a bridge between language teaching research and psychology can be built up. Fortunately, Pygmalion effect can serve this function.

The application of putting Pygmalion effect into junior English teaching can put teachers potential to the fullest play. At the same time, Pygmalion effect can make a great contribution to junior English teaching. Hereafter are some functions of Pygmalion effect.

\subsection{The Construction of a Harmonious Teacher-Student Relationship}

The application of Pygmalion Effect can be of great benefit to the establishment of a harmonious teacher-student relationship. This effect requires teacher goes deeper into the students, which contributes to a closer relationship. Teachers can know students down-earthly and understand them, which in turn will gain their support. This can be very helpful for mutual communication.

\subsection{The Inspiration of Students' Intrinsic Motivation of Learning}

The application of Pygmalion effect can transfer the requirement that society and school needs into their own need for learning and a kind of positive attitude towards learning, which can strengthen the original need of learning. In this way, the intrinsic motivation of learning can be inspired.

Once formed the motivation of learning, a strong will of overcoming the difficulties in English learning will come into being as well.

\subsection{The Enhancement of Confidence}

From the perspective of psychology, everyone has the mental need to be recognized by the society and praised by other people, hence they can respect their importance and social values. They make self-judgment via others' responses.

Pygmalion effect can enhance students' confidence in English learning. For Pygmalion Effect focuses on the mental suggestion to learners, the encouragement made by the teacher will increase the students' confidence and desire to knowledge acquisition.

Once be full of confidence, students can learn English more actively and initiatively.

\section{The Application of Pygmalion Effect in English Class}

Considering the Pygmalion Effect and based on the theories and researches mentioned above, what teachers should do is to care much about students inner mind, show love to them, encourage them patiently and make good use of all kinds of different ways and teaching tools to inspire them to learn English heart and soul. In order to fulfill them, English teachers play a very important role. It is teachers' duty to change the traditional teaching mode to meet the needs of present society, speed up the teaching reforms and enhance the teaching efficiency and result.

\subsection{Proper Expectations}

From the experiment, the conclusion implies that "the students live up, or down, according to their teachers' expectancy for them (Gerald D. Baxter, John K Bowers, 1985)." and that expectancy has great magic power in realizing their goals.

Being a teacher for one day, be a father forever. This traditional principle seems to give teachers the highest authority. Some teachers require their students to do everything according to their expectations, which is inappropriate in teaching. Teachers should raise proper expectations to students. On the online National Teaching and Learning Forum, there is a commendation which cited that when teachers expect students to do well and show intellectual growth, they do; when teachers do not have such expectations, performance and growth are not so encouraged and may in fact be discouraged in a variety of ways. The so-called "proper expectations" means that teachers' expectations should fit for students' "Zone of Proximal Development (ZPD)".

"Zone of Proximal Development (ZPD)" refers to the range between students' present developing level and the developing level they can get through efforts. This is proposed by a Soviet psychologist named Lev Vygotsky. He presented that "The difference between the actual development level as determined by independent problem solving and the level of potential development as determined through problem solving under adult guidance, or in collaboration with 
more capable peers”(Vygotsky, 1978). He thinks that students' development can be promoted to the utmost extent only if education fit for students' "Zone of Proximal Development".

According to Stevick (1998), expectations influence the ways in which teachers evaluate students, behave toward students and make decisions about students. These expectations create a subjective reality in which students tend to perform up to expectations. Pygmalion effect asserts that one's expectations about a person behave and achieve in ways that confirm those expectations.

If being highly expected, students cannot satisfy teachers' expectations and cannot experience the pleasure of success. If being lowly expected, students' self-esteem can be hurt, which cannot arouse their motivation. Therefore, teachers should have proper expectations to students. Since things change forever, so do students. Each student is a unique exists in this world and has his own character. We also know that quality education aims to enhance the quality of every student. In this sense, teachers had better propose specific expectations to each student according to his own character and personality.

For instance, for students who are adept at English, teachers should have higher expectations to them. Besides gaining high marks, those students are required to be good at pronunciation and language communication. For students who are plain at English, teachers should have an ordinary expectation. For those who are poor at English, teachers should pay more attention to enhance their basic knowledge of English.

From another aspect, teachers' teaching effects can be fully represented in their expectations to their students. It's not just concerned with their marks, but many aspects, such as their thought patterns, ethnics and so on.

Express proper expectations at the right time, English teaching can be greatly improved. What's more, students' potential can be put into full play and developed.

Stevick (1998) speaks of bringing to language teaching a concern for "deeper aims", for "pursing new 'life-goals", not just for reaching certain language goals, but also can educate learners to lead more satisfying lives and to be responsible for society.

\subsection{Patient Love}

As a famous saying goes, without love, there is no education. That is, love itself is a kind of education. Teachers' love for students is the key content of teaching. Makarento, Anton Semiohovich (1888 1939), a famous educationist, once said that being a teacher, he should love each student and respect each student to the utmost extent. To impart knowledge and educate people is the cause of a project of vital and lasting importance. Teachers are the engineers of human spirits. It's an honor for each teacher to love each student. To love students means to enjoy communicating with them, to watch them carefully, to understand students' characters and personalities as well as their hobbies, their happiness and sorrows.. During the course of English teaching, different requirements are raised for various students. Encouragements and aids are given to those who are in need, thus students would be enjoying their English learning.

During the process of teaching, the teacher should always remember the power of love. When he appraises some student, let the student feel all the comments are from the bottom of his heart. When the teacher criticizes the student, he should make the student know he does this because he has expectancies for him. The criticism should come with the appraisal so that the student can see hope. In addition, eye contact should be taken into account, which also produces encouragement to the student.

During my internship, there is a common phenomenon that the English teacher only loves part of their students, and accordingly, these students who are loved show great interest in English learning and also good at it. The other students don't like English, either their English teacher, hence not good at English at all, which seems to have formed a vicious circle.

In order to earn a living, many parents flooded into first-rate cities, which is the very cause of a large amount of stay-athome children. For these kinds of students, they are in desperate need of motherly and fatherly love. Then, during the time they are learning at school, a kind of emotional transfer comes into being. They are largely dependent on their teachers and want to be loved by their parents. For them, teachers should care more about their inner world, as they may be more sensitive then other students. The more love they gain from their English teachers, the more active and confident will they be in English learning. For students who are introvert, English teachers should encourage them to show themselves. English learning needs passion and enthusiasm. Being active will be very helpful in English learning, for language learning is a process which needs practical practice. For students who come from rural areas, teachers had better offer them more opportunities, help them get rid of inferiority and enhance their confidence.

In this way a good teacher should love each student, not just some students. Having done this, students will be very happy to learn and their English will be improved. Teachers should have more exploration on teaching via wisdom and love. This is really the challenge to teachers in English teaching.

\subsection{Appropriate Emotional Communication}

Xia Gaizun, a famous and respected educator, takes the relationship between education and emotion as the relationship between a pool and water. A pool cannot be a pool without water. There is no education without feelings and emotion.

There is an investigation that one quarter of students' marks can be illustrated by personal emotion. Earl Stevick (1998) believed that compare with learning materials, teaching techniques and language analysis, learners' inner emotion and interpersonal relationship play a more important role in successful learning. 
In the year 1977, Krashen proposed Affective Filter Hypothesis, which indicate that emotion influence second language acquisition directly and can filter the language input. Positive emotion can create a psychological state which is good for study, however, negative emotion cannot (Wang Qiong, 2005)..

English classroom teaching is the process of emotional communication between teachers and students. It initiates a harmonious and cheerful teaching atmosphere. Students can work at learning activity with happiness and interest. During the English classroom teaching, not only teachers' words but also their deeds can arouse students' emotional experience. Teachers attitude plays a great role to students. Imagine teachers come into the classroom with a big smile, greeting with kindness and enthusiasm, giving lessons with inspiration, explaining with patients. All of this can make their lessons lively interesting and attractive. Teacher's positive emotion can stimulate the interest of students' learning and happy emotions. It also can make students take an active part in the classroom practice and accept knowledge amusedly. Students' active behavior will in turn encourage teachers to be more enthusiastic and energetic. The students' happy emotions affect teachers and teachers' happy emotions promote students' study, and then a good cycle is formed. It plays a positive role in making English classroom teaching excellent in middle schools.

For example, eye-contact is a powerful means of emotional communication. When students are nervous while they are doing a presentation, encouraging eye-contact will boost their confidence effectively. When students accomplish some achievements, an eye-contact of praise will be a driving force for them to pursue their goals.

Every emotional action corresponds with some cognitive action and vice versa. Teachers should have an appropriate emotional communication with their students on a regular basis. Being in a good state can make a good preparation for their English learning and can undoubtedly make a difference.

\subsection{Full Respect}

In the book Modern Educational Psychology, Chen Qi and Liu Rude said that once knowing the meaning of respect and humiliation, they will be the most powerful stimulus to their inner world. This is also true of Pygmalion effect. So in English teaching, a full respect to students is inevitable.

Mutual respect between teachers and students not only reflects the new attitude towards learning of modern education, but also helps to promote the teaching demonstration and construct the positive teaching psychological circumstances with harmony, demonstration, freedom, and relaxation. To respect students, teachers should respect students' characters and personalities; meanwhile, they should keep their self-respect and self-confidence intact. Students' individual consciousness and latent energy should be developed so as to make them learn pleasant and creatively in the classroom. For example, when teachers are planning for the teaching contents, the teaching contents should fit for students at each level. From internship, I know that junior middle school students are not mature. They do not have the ability to understand and judge things, but they have their own criteria to value things. They would like to communicate with people who use a tone of a friend not a teacher. It's easy for them to accept things when teachers negotiate with them, but not when they are ordered to do this or that. A famous educator once said: "Students will respect me more as a teacher if they see that I treat them as friends and that I treat every student equally based on a consistent discipline plan". So teachers show full respect to their students, thus can be very helpful in both their English learning and the formation of their personality and values.

\section{Conclusion}

Pygmalion Effect means that "you get what you expect, which indicates that people tend to live up to what is expected of them and tend to do better when treated as if they are capable of success. Pygmalion Effect, previously applied in management and medication, has gained predominant achievements. Meanwhile, it also can be applied into education. Being introduced into education until 1836, Pygmalion Effect becomes the overall representation of the art of education. It is also true of English teaching and learning, for English being a brand-new language for our Chinese learners. However, the status quo is that Pygmalion Effect is still a fresh conception to most of English teachers. From this perspective, the connotation of its theme needs to be deepened during the process of English teaching. With proper expectations, patient love, appropriate emotional communication and full respect, the quality of English learning can be raised surely, which can not only lay a good foundation to their English learning but also to their life-long learning. In a nutshell, the thesis focuses on the application of Pygmalion Effect in junior English learning. It fits for junior middle school students considering their age character. It will be further used in high school English teaching and vocational education in the years to come.

\section{References}

Brophy. R. (1983). Understanding Emotions. Cambridge.

Chen, Q., \& Liu, R. (2007). Contemporary Educational Psychology. Beijing Normal University Press.

Daragh, M., \& Clifton, C. (2001). The Pygmalion effect reconsidered: its implications for education, training and workplace learning. Oxford.

Gerald, D. B., \& John, K. B. (1985). Beyond self-actualization: the persuasion of Pygmalion. Training and Development Journal.

Vygotsky, L. (1925). Thought and Language. Beijing Language and Culture University Press.

Lu, J. (2000). Affective Education Psychology. Shanghai Educational Press. 
Makarenko. D. (1957). Educational Papers of Makarenko. People’s Education Press.

Rosenthal, F., \& Jacobsen, S. (1968). Pygmalion in the Classroom. Oxford; New York.

Stevick, T. (1998). Working with Teaching Methods: What's at Stake? Cambridge.

Su, Y.(2010). The Impact of Pygmalion Effect on Junior English Teaching. Journal of Inner Mongolia University, 4.

Wang C. (2005). The Compensation Hypothesis in English Listening, Speaking and Reading. Guangxi University Press. (10).

Wang, Q. (2005). Affective Filter and English Teaching. Journal of Xiang Chao, 3.

Wang, L. (2008). The Enlightenment of Pygmalion Effect. The Journal of Reading and Writing, 1. 